\title{
BMJ Open Using in situ simulation to improve care of the acutely ill patient by enhancing interprofessional working: a qualitative proof of concept study in primary care in England
}

Amy Halls, ${ }^{\oplus 1}$ Mohan Kanagasundaram, ${ }^{2}$ Margaret Lau-Walker, ${ }^{1}$ Hilary Diack, ${ }^{2}$ Simon Bettles ${ }^{1}$

To cite: Halls A,

Kanagasundaram M, LauWalker $\mathrm{M}$, et al. Using in situ simulation to improve care of the acutely ill patient by enhancing interprofessional working: a qualitative proof of concept study in primary care in England. BMJ Open 2019;9:e028572. doi:10.1136/ bmjopen-2018-028572

- Prepublication history and additional material for this paper are available online. To view these files, please visit the journal online (http://dx. doi org/10.1136/bmjopen-2018028572).

Received 18 December 2018 Revised 15 June 2019 Accepted 28 June 2019
Check for updates

\section{(c) Author(s) (or their} employer(s)) 2019. Re-use permitted under CC BY-NC. No commercial re-use. See rights and permissions. Published by BMJ.

${ }^{1}$ Faculty of Health and Medical Sciences, University of Surrey, Guildford, UK

${ }^{2}$ Health Education England Kent, Surrey and Sussex, Crawley, UK

Correspondence to

Dr Amy Halls;

a.v.halls@surrey.ac.uk

\section{ABSTRACT}

Objective Acutely unwell patients in the primary care setting are uncommon, but their successful management requires involvement from staff (clinical and non-clinical) working as a cohesive team. Despite the advantages of interprofessional education being well documented, there is little research evidence of this within primary care. Enhancing interprofessional working could ultimately improve care of the acutely ill patient. This proof of concept study aimed to develop an in situ simulation of a medical emergency to use within primary care, and assess its acceptability and utility through participants' reported experiences.

Setting Three research-active General Practices in south east England. Nine staff members per practice consented to participate, representing clinical and non-clinical professions.

Methods The intervention of an in situ simulation scenario of a cardiac arrest was developed by the research team. For the evaluation, staff participated in individual qualitative semistructured interviews following the in situ simulation: these focused on their experiences of participating, with particular attention on interdisciplinary training and potential future developments of the in situ simulation.

Results The in situ simulation was appropriate for use within the participating General Practices. Qualitative thematic analysis of the interviews identified four themes: (1) apprehension and (un)willing participation, (2) reflection on the simulation design, (3) experiences of the scenario and (4) training.

Conclusions This study suggests in situ simulation can be an acceptable approach for interdisciplinary team training within primary care, being well-received by practices and staff. This contributes to a fuller understanding of how in situ simulation can benefit both workforce and patients. Future research is needed to further refine the in situ simulation training session.

\section{BACKGROUND}

Medical emergencies within primary care are rare, a number largely unknown. One study
Strengths and limitations of this study

- This is a novel approach to exploring the use of in situ simulation within the primary care setting.

- The qualitative approach is appropriate for exploring participants' experiences and perceptions-multiple coders during analysis strengthened the rigour of the study.

- All centres were research-active, accessed through existing relationships with the research team. It is possible these centres were particularly confident in their ability and therefore willing to participate.

- As participation in the simulation was not compulsory, we do not know how individuals who did not participate would have experienced the event: therefore, care should be taken in generalising findings beyond this first proof of concept study.

found $6 \%$ of all out of hospital cardiac arrests (OHCAs) were in primary care, viewing this as a significant number and suggesting primary care providers have an important role in managing OHCA. ${ }^{1}$ Their management requires good teamwork, communication and effective use of available resources by the whole primary care team ${ }^{2}$ and there has been a growing interest in the application of simulation-based training to non-clinicians and the organisation as a whole. ${ }^{3}$

There is little published data on the acceptability or impact of multidisciplinary simulation-based medical emergencies training in general practice, most training being aimed specifically at clinicians. Training provides the opportunity to practise a variety of skills in a consequence-free environment, and team training enhances its effectiveness. ${ }^{4}$ Simulation allows for the practice of skills needed in emergency situations without relying on clinical opportunity ${ }^{5}$ and can reinforce 
psychomotor and critical decision-making skills ${ }^{6}$ as well as training the management of complex medical situations. ${ }^{78}$ Previous research using simulation-based medical emergencies training showed an improvement in general practitioners' (GPs') reported management and confidence in responding to an emergency, and a positive impact on both from non-clinical staff. ${ }^{2}$ Simulation-based medical emergency training has also allowed non-clinicians to gain experience and appreciation for the demands of patient care, ${ }^{3}$ emphasised the importance of defining team structures and processes, ${ }^{9}$ and provided participants with the opportunity to develop non-technical skills such as effective teamwork and communication. ${ }^{10}$ Simulated exercises have the potential to allow individuals to practise the management of emergencies within a team setting, and also allows team to analyse and adapt their own performance. ${ }^{11}$

In an interdisciplinary team, members work closely together and communicate frequently, organised around a common set of problems. ${ }^{12}$ In recent years healthcare workers have been encouraged to move away from 'silo' roles towards an environment which is more interprofessional in order to improve patient care ${ }^{13}$ While there are bodies of literature on interprofessional education and medical simulation, there is a paucity of literature which links the two. With minimal opportunities for health professionals to interact and engage in multiprofessional scenarios prior to real-life experience,${ }^{14}$ it is important that the opportunities provided are seen as beneficial to all the participants. In situ simulation has been used to develop individual and team learning across clinical and non-clinical areas ${ }^{15}$ : bringing portable equipment to the actual clinical environment allows simulation training to be delivered to teams who may not benefit from the educational tool otherwise. ${ }^{16}$ The use of a high-fidelity patient simulator in conjunction with a well-designed scenario enables near-perfect realism and is appropriate for use as a continuous professional development activity. ${ }^{17}$

This proof of concept project aimed to develop an in situ simulation scenario of a medical emergency and explore the views of clinical and non-clinical staff as to whether it is feasible and beneficial to use as an interprofessional training format within primary care.

\section{METHOD}

A qualitative evaluation of an in situ simulation intervention exercise was designed to explore and understand the views of primary care staff as to their experiences of using simulation to deliver interdisciplinary training, focusing on appropriateness and acceptability.

\section{SETTING}

Four research-active general practice centres within Health Education England Kent, Surrey and Sussex (HEEKSS), known to the research team, were approached regarding participation. Each was visited by AH to answer questions and ensure the space available was appropriate for the simulation. One centre withdrew before filming; the remaining three participated between May and August 2018. The practice managers and senior GPs from each centres were responsible for recruiting staff members willing to participate. Centres were recompensed $£ 500$, an amount set by the research funder (HEEKSS) to cover costs incurred from participation (such as ensuring additional staff were on duty to allow for the centre to remain open throughout the simulation).

\section{INTERVENTION}

A simulation of a medical emergency was designed by the research team and further developed in collaboration with the actors. SB, lead for simulation education and MK, a GP and Simulation Lead for Post Graduate Medical Education at HEEKSS, developed the clinical outline of a cardiac arrest scenario which would occur in the waiting room of the GP centre. The character $\mathrm{Mr}$ Hughes would collapse, witnessed by his 'wife'. A third actor would play a patient who would become increasingly annoyed at the perceived inconvenience. During rehearsals with the wider research team and the actors the clinical skeleton underwent elaboration to include a greater medical history for the characters involved, to pre-empt questions which could be asked by the research participants. In order to maximise realism, human interaction and real world benefit, the simulation used actors and the centres' own emergency equipment. In the finalised scenario, the actor playing Mr Hughes would collapse in the waiting room, ensuring he was close to a dividing screen: this would be immediately moved by a member of the research team to reveal a high-fidelity mannequin (Laerdal ()) dressed in identical clothing to allow participants to use chest compressions and their defibrillator. The actor would move out of the way and later became the emergency call handler when a member of staff 'phoned' 999 using the handset provided.

Cameras were positioned in the waiting room to capture the simulation: the research team remained in the waiting room and could view the simulation via a laptop and were able to tag the recording to capture significant moments, important for the subsequent debrief. SB and MK had laminated sheets containing clinical information about Mr Hughes (such as his blood pressure) which would be provided to participants when required. This film was used in the postsimulation debrief, which occurred in a separate private room, with all participants to reinforce the learning objectives and critique performance in an objective atmosphere. ${ }^{6}$ Participants were reminded that the training was not an individual assessment. During the simulation, all members of staff who had consented to participate in the research had an active role-no one had the role of observer.

The simulation ran for approximately $20 \mathrm{~min}$ followed by a short break and a debriefing session of approximately $45 \mathrm{~min}$, using 'the diamond' debriefing method as 
Table 1 Participant characteristics (grouped data)

\begin{tabular}{lll}
\hline Role & Female participants & Male participants \\
\hline General practitioner & 6 & 4 \\
Nurses and healthcare assistants & 5 (1 unable to be interviewed) & 1 \\
Non-clinical roles (eg, general practice & 11 (1 unable to be interviewed) & 0 \\
manager, receptionist, administration) & & \\
\hline
\end{tabular}

a guide for structure. ${ }^{18}$ Face-to-face interviews occurred within a fortnight, depending on participant availability, and were audio-recorded.

\section{Patient and public involvement}

Patients and the public were not involved in the design or planning of the study.

\section{Evaluation}

Each participant consented to a semistructured face-toface interview (see online supplementary appendix 1) with $\mathrm{AH}$, an experienced qualitative researcher. Interviews were transcribed verbatim and analysed using inductive thematic analysis. ${ }^{19}$

AH read each transcript and coded line by line, using NVivo to manage the dataset. Codes were derived inductively from the data and grouped to produce the initial coding frame. Codes and theme/subtheme definitions were iteratively developed by AH and SB. Data saturation was achieved, and the coding manual fitted all of the data.

All staff members gave informed consent to participate in the simulation, debrief, and interview. While on site, care was taken to ensure members of the public were aware it was a training session and that the 'patients' involved were actors: signs were put in entrances, and on doors and walls in corridors and waiting areas, reception staff informed patients as they checked in for their appointments, and members of the research team were available to answer any questions in the hope that members of the public were shielded from any distress. The cameras used for filming the scenario were positioned in such a way that they only captured a small section of the waiting room and not members of the public.

\section{RESULTS}

Each centre had nine staff members volunteer to participate in the simulation: two participants were unable to be interviewed during to lack of availability. Table 1 shows the total number of clinical and non-clinical staff members who participated.

Thematic analysis identified four themes relating to the participants' involvement in the simulation. The themes and subthemes are shown in table 2. Illustrative quotations are provided.

\section{Apprehension and (un)willing participation}

All three centres reported limited exposure to simulation as a pedagogic approach; only junior clinicians had experienced simulation as part of their hospital training. Participants knew they would be involved in a simulation but had no further details as to the content of the scenario in advance.

\section{Apprehension prior to event}

Both clinical and non-clinical participants expressed anxiety felt prior to participating, both on an individual level and for the staff as a whole. Participants did not know what medical emergency the simulation would involve and this 'fear of the unknown' was off-putting to some. Anxiety was also due to being aware the simulation would be filmed and shown to the group.

I think it's because we were being videoed, if we weren't being videoed and I think that's a personal thing rather than or being worried professionally, if this was sort of just another BLS [basic life support] type simulation we do that annually, I wouldn't have

Table 2 Themes and subthemes

\section{Theme}

1. Apprehension and (un)willing participation

2. Reflection on the simulation design

3. Experiences of the scenario

4. Training

\section{Subtheme}

1.1 Apprehension prior to event

1.2 Fear of assessment

1.3 (Un)willing to participate

2.1 Simulated patients

2.2 In situ simulation elements

2.3 The transferability of knowledge

3.1 Clinical aspects

3.2 Non-clinical aspects

4.1 Clinical and non-clinical staff training

together

4.2 Changes postparticipation
Additional subthemes (where applicable)

1.1.1 Fear of the unknown

1.1.2 Concerns about filming 
minded that, because we were being videoed we didn't quite know what to expect and it was all you know we were told 'oh they're on site and they're setting up' and there was bit of secrecy around it which sort of increased the stress levels but I think once we were in the situation in the scenario in the situation it was fine. (Clinical participant)

\section{Fear of assessment}

Concerns that prior to the simulation it felt like a test were expressed by both clinical and non-clinical members of staff. Individuals were wary about how they would be viewed by colleagues and the research team. However, most people who felt this way at the beginning had a different view afterwards.

I think you'd always be nervous if something real happened like that but, as far as it being like a test, which I think we all probably thought, oh gosh, this is like an exam or a test type thing, it wasn't really. (Non-clinical participant)

\section{(Un)willing to participate}

Despite expressing anxiety around participation, most people were enthusiastic, often because of its learning opportunity. Others were less willing, suggesting colleagues who would find it more useful.

I did volunteer. Back in medical school I found they were really helpful. It's always excruciating, especially watching it back, but it's worth it for the learning. (Clinical participant)

\section{Reflection on the simulation design \\ Simulated patients}

The actors were highly praised for their realistic portrayal of patients: they enabled staff to fully participate within the scenario and enhance its psychological fidelity. However, when participants realised who the 'ill' actor was, he potentially became less believable. As the specifics of the scenario were unknown to participants beforehand, there was scope for people to be surprised and to demonstrate flexibility.

The element of surprise is good, and the fact that you managed to keep that other actress well away so we didn't even know that she was, it was really clever [...] when someone collapses on the floor we're not really used to having hysterical relatives and people fighting that doesn't normally happen so that was, that was good to see that we still managed to handle it as well as we did. (Non-clinical participant)

\section{In situ simulation elements}

Participants highlighted the importance of familiarity with their own equipment and being in a simulated emergency which was as realistic as possible (for example, the mannequin being fully dressed). The use of own equipment was valued by all members of staff as a fundamental element for learning. The unique space constraints in each centre provided an additional challenge, but one viewed as beneficial.

I was a bit keen to put the [defibrillator] pads on before the man had his bare chest. But I know that I've got to put the plastic pads on, but I was obviously faced with strange things. (Clinical participant)

where difficulties and insight is coming is using your own equipment, knowing where things are knowing the processes, knowing who is, who does what. (Clinical participant)

\section{Transferability of knowledge}

Staff noted that the simulation session provided them with a safe environment in which they could practice their skills and identify areas for improvement. For non-clinical staff, simulation showed the importance of a team approach and being able to assist when needed.

I think everybody needs to go through this because it's a learning curve for even a receptionist, as we keep saying we're just receptionists, we're not medically trained but, when push comes to shove, you need to help. (Non-clinical participant)

\section{Experiences of the scenario \\ Clinical aspects}

Many participants felt that the clinical aspects were the most important learning aspects of the training, expressing reassurance that staff were competent in their roles and that equipment was working and used successfully.

Seeing how my colleagues react in a crisis situation, it's nice to know they do know what they're doing [laughs]. (Non-clinical participant)

\section{Non-clinical aspects}

Teamwork, and the number of people participating, were viewed positively by participants. It was seen as enhancing the fidelity of the simulation and providing a useful learning opportunity.

The fact that we work as a team, I like that, I mean we do quite often hit the green [emergency] button and all sort of do it and that's so we are used to you know working as a team and each of us having our own job to do when if it happens. So I was pleased that it went so well this time round. (Non-clinical participant)

\section{Training}

All three centres identified basic life support training as the only joint 'clinical' teaching; however, the sessions were about individual proficiency in the tasks rather than team work.

Clinical and non-clinical staff members training together

Both clinical and non-clinical members of staff felt it was beneficial to have joint training sessions, especially 
given the siloed nature of the primary care environment. However, offering trainings for all staff together was felt to not always be practical, in part due to the difficulties in closing the centre.

\section{Changes postparticipation}

All centres successfully managed the emergency situation: however, some participants had concerns over familiarity with equipment. The idea of further training, specifically focusing on equipment, was voiced by staff at all three centres, with suggestions as to how this could be addressed, such as additional opportunities for using centre-owned equipment during training sessions. It was expressed that everyone on site should know how to use emergency equipment and that trainings would not need to be time-consuming in order to achieve greater familiarisation with equipment.

I kind of veered towards that everyone should be trained to using the equipment. Because I know that I'd like to help, if I was the only one here or if there were two of us here, I couldn't leave a person. (Nonclinical participant)

Management of staff was identified as a potential area for improvement. Participants acknowledged this was difficult at certain points during the scenario as people who would normally be involved were not participating/ on duty that day. This highlights the need for there to be flexibility in terms of planning for managing an emergency so all staff understand their role. Leadership was highlighted by several participants as a focus for the future.

I think reception staff erm you know often they haven't had simulation training where you've been in involved in something cardiac arrest or something they've learned a lot and enjoyed the experience but yeah I think um I think as a practice now we will go away and each of us the nurses will think about it, the receptionist will think about it, the doctors will think about it and then try and make changes where there needs to be changes. (Clinical participant)

There was a concern that non-clinical members of staff did not feel as confident to deal with the emergency as clinical colleagues. While all staff members undergo mandatory BLS trainings, it was suggested that this could be done more frequently in-house.

I think it's good to encourage not just your clinical staff but your admin staff to do things like this because it is quite out of your comfort zone and yes, I think it is good to just have the knowledge behind you. (Non-clinical participant)

\section{DISCUSSION}

This unique study has shown proof of concept that in situ simulation could be an acceptable and feasible way of developing interprofessional skills in the primary care workforce and as such have the potential to improve patient care. The simulation showed all participating centres could potentially successfully manage a medical emergency as well as meeting additional patient demands. While many participants, both clinical and non-clinical, were apprehensive beforehand, all found it to be a beneficial training experience and were enthusiastic about its potential benefit to learning. While the in situ set up proved challenging, it increased the perceived fidelity of the simulation. No patients reported any distress either to the research team or centre staff. Overall, participants were reassured that staff displayed competence in their roles and that the centres' own equipment was used successfully.

\section{Strengths and limitations}

All centres were research-active, accessed through existing relationships with the research team. It is possible these centres were particularly confident in their ability and therefore willing to participate. Also, all centres were large (15 000+registered patients) and urban: we do not know how smaller, more rural centres would have fared. As participation in the simulation was not compulsory, we do not know how individuals who did not participate would have experienced the event: therefore, care should be taken in generalising findings beyond those that participated. However in each centre there was a good range of different roles included. The qualitative method is appropriate for exploring participants' experiences and perceptions-multiple coders during analysis strengthened the rigour of the study.

\section{Comparison with existing literature}

Evidence around the efficacy of in situ simulation is emerging, and existing research is promising, but this is a relatively new area ${ }^{15}$ : there is very limited research on investigating the value of high-fidelity simulation within primary care, providing clinicians with the practical skills and confidence to manage emergencies within their surgeries. One project focusing on this led simulation-based workshops covering more commonly encountered medical emergencies and required participants to locate and use their own equipment and medication ${ }^{20}$ : the results showed many participants knew how to respond 'in theory' but were unable to demonstrate practical aspects quickly and safely. This training is particularly important for time-critical illnesses. Previous research with healthcare assistants showed participants felt simulation-based training had reinforced their clinical knowledge and ability as well as adding to it. ${ }^{21}$ Increased confidence following in situ training has been shown to remain at an 8 -week follow-up ${ }^{22}$ thus indicating this type of training has lasting benefits towards managing the acutely ill patient.

By training clinicians in situ, using their own equipment, centres are able to see how well their space works and also assess human-factor elements. ${ }^{23}$ Problems such as clinical staff struggling with equipment are only going 
to be identified through actual use, and therefore it is paramount staff develop familiarity with equipment. Established resuscitation courses support individuals in managing emergencies, but a focus on their particular teamwork and communication in their actual day to day role cannot be provided, hence in situ simulation offers an important complement. ${ }^{24}$

Previous research has identified training as improving performance ${ }^{25}$ and it is likely this can be translated into clinical practice. Healthcare professionals are trained predominantly in uniprofessional settings, yet have to work collaboratively in the practice environment; they may find they work side by side rather than together as an efficient team. ${ }^{26}$ Teams are dynamic and require commitment to work and maintain: there is a need to understand other people's roles. ${ }^{27}$ There is a growing awareness that patient safety in healthcare relies on the ability of individuals to collaborate with other professionals. This simulation allowed participants to view their colleagues in action and learn how they can best support one another in the management of an acute medical emergency. This supports previous findings in which participants were able to highlight their own strengths and weaknesses and be able to continually adapt to others in the team. ${ }^{28}$ Team training has been identified as a high priority for the future of simulation. ${ }^{29}$

When comparing teams, there was no consistent difference as to whether teams had been trained in their hospital or in a simulation centre. The advantages of local training are lower cost and no travel time or expenses (from the participants), the inclusion of healthcare assistants, receptionists and porters. All centres made changes to their staff training and equipment following the simulation session. These changes were easily identified, predominantly on increasing staff familiarity with equipment and offering more frequent training sessions than the mandatory BLS updates. Providing more opportunities for clinical and non-clinical members of staff to train together would enhance interprofessional working and reinforce understanding of the others' roles. Previous research referred to the 'emotional neutrality' of GP receptionists which can help to avoid exacerbating negative behaviour from annoyed patients. ${ }^{30}$ It is important staff are able to tailor that offering to the needs of individual patients. Receptionists' work is complex and demanding and effective teamwork among receptionists should be recognised and developed. ${ }^{31}$

A limitation with this study is the lack of comparison to training where clinical and non-clinical members of staff learn with their professional peers rather than the whole centre team. While we have shown that interprofessional training has been beneficial in this instance, we are unable to show if this is definitively better than the more common profession-specific training. Previous research has shown that the voice of doctors can be dominant even if individuals are aware of this, which has the potential to be detrimental to the learning of others. ${ }^{32}$

\section{Implications for research and practice}

This research has emphasised the potential importance and benefits of team training through in situ simulation which includes all staff members within the GP surgery. The use of in situ simulation was positively received, although did cause apprehension for many participants which may impact on recruitment in future studies. Future research in the form of a feasibility study will need to explore whether in situ simulation is as well-received in smaller centres and consider whether improvements in teamwork would only apply to these teams, or also different teams, given changes in staff. ${ }^{26}$

\section{CONCLUSION}

Primary care staff members were given the opportunity to experience participating in the care/management of an acutely ill patient in a safe environment. From this, they were able to suggest changes in their workplace (such as increasing all-staff familiarity with on-site equipment) and this should benefit their performance, and as such the care of the patient, should they be faced with such an emergency in the future. Strengths identified in the debrief session can be highlighted and good practice can be shared with colleagues. The use of actors and fully involving both clinical and non-clinical members of staff builds upon previous research to form a fuller understanding of how in situ simulation can benefit both the primary care workforce and patients.

Acknowledgements We are grateful to the general practice centres and their staff who participated in our research project, and to the actors who contributed to its development and success. Thank you to Corina Downing, for producing the 999 call handler script and Cath Taylor for insightful comments on the draft manuscript

Contributors SB was responsible for all aspects of the study including design, data collection and analysis. AH led on data collection, analysis and interpretation, and manuscript preparation. SB and MK were responsible for the clinical aspects of the research. $\mathrm{HD}$ implemented the study and $\mathrm{ML}-\mathrm{W}$ was involved in the development of the study design. All authors commented on manuscript drafts and approved the final version.

Funding The Primary Care Simulation Education Project was funded by Health Education England Kent, Surrey and Sussex. The views expressed are those of the authors and not necessarily those of HEEKSS.

Competing interests None declared.

Patient consent for publication Not required.

Ethics approval Ethical approval was received from the Faculty of Health and Medical Sciences ethics committee (ref: 1349-FHMS-17).

Provenance and peer review Not commissioned; externally peer reviewed.

Data sharing statement No additional data is available.

Open access This is an open access article distributed in accordance with the Creative Commons Attribution Non Commercial (CC BY-NC 4.0) license, which permits others to distribute, remix, adapt, build upon this work non-commercially, and license their derivative works on different terms, provided the original work is properly cited, appropriate credit is given, any changes made indicated, and the use is non-commercial. See: http://creativecommons.org/licenses/by-nc/4.0/.

\section{REFERENCES}

1. Ong ME, Yan X, Lau G, et al. Out-of-hospital cardiac arrests occurring in primary health care facilities in Singapore. Resuscitation 2007;74:38-43. 
2. Strachan AN, Graham AC, Hormis AP, et al. What were the perceptions of primary care teams on learning from a single multidisciplinary simulation-based training intervention? Educ Prim Care 2011;22:229-34.

3. Cooper J, Vogt JW, Simon R, et al. Team training for healthcare administrators using full environment simulation. International Meeting on Medical Simulation 2004.

4. Salas E, DiazGranados D, Weaver SJ, et al. Does team training work? Principles for health care. Acad Emerg Med 2008;15:1002-9.

5. Mugford B, Martin A, Owen H. Simulation training in emergency medicine. An important need for primary care training. Aust Fam Physician 2004;33:279-80.

6. Chronister C, Brown D. Comparison of Simulation Debriefing Methods. Clin Simul Nurs 2012;8:e281-e288.

7. Pietsch U, Schneider H, Schuhwerk W. Evaluation of multidisciplinary simulation-based team training: The way forward for training icu teams. Intensive Care Med Exp 2015;3(Suppl 1):A860.

8. Kneebone RL, Scott W, Darzi A, et al. Simulation and clinical practice: strengthening the relationship. Med Educ 2004;38:1095-102.

9. Small SD, Wuerz RC, Simon R, et al. Demonstration of high-fidelity simulation team training for emergency medicine. Acad Emerg Med 1999:6:312-23

10. Watmough $\mathrm{S}$, Box $\mathrm{H}$, Bennett $\mathrm{N}$, et al. Unexpected medical undergraduate simulation training (UMUST): can unexpected medical simulation scenarios help prepare medical students for the transition to foundation year doctor? BMC Med Educ 2016;16:110.

11. Fox R, Walker JJ, Draycott TJ. Medical simulation for professional development--science and practice. BJOG 2011;118 Suppl 3(Suppl 3): $1-4$.

12. Hall $P$, Weaver L. Interdisciplinary education and teamwork: a long and winding road. Med Educ 2001;35:867-75.

13. Myron R, French C, Sullivan P, et al. Professionals learning together with patients: An exploratory study of a collaborative learning Fellowship programme for healthcare improvement. $J$ Interprof Care 2018;32:257-65.

14. Robertson J, Bandali K. Bridging the gap: enhancing interprofessional education using simulation. $J$ Interprof Care 2008;22:499-508.

15. Rosen MA, Hunt EA, Pronovost PJ, et al. In situ simulation in continuing education for the health care professions: a systematic review. J Contin Educ Health Prof 2012;32:243-54.

16. Weinstock PH, Kappus LJ, Garden A, et al. Simulation at the point of care: reduced-cost, in situ training via a mobile cart. Pediatr Crit Care Med 2009;10:176-81.

17. Hssain I, Alinier G, Souaiby N. In-situ simulation: A different approach to patient safety through immersive training. MJEM 2013;15:17-28.
18. Jaye P, Thomas L, Reedy G. 'The Diamond': a structure for simulation debrief. Clin Teach 2015;12:171-5.

19. Braun V, Clarke V. Using thematic analysis in psychology. Qual Res Psychol 2006;3:77-101.

20. Forde E, Bromilow J, Wedderburn C. Practical management of emergencies in primary care: taking simulation out of the classroom and into real-life environments. BMJ Simulation and Technology Enhanced Learning 2018;4:43-4.

21. McKenzie Smith M, Turkhud K. Simulation-based education in support of HCA development. British Journal of Healthcare Assistants 2013;7:392-7.

22. Forde E, Bromilow J, Jackson S, et al. Managing emergencies in primary care: Does real-world simulation based training have any lasting impact? BMJ Simulation and Technology Enhanced Learning 2017 (Online First: 07 Oct 2017).

23. Eastwick-Field P. No more tick box resuscitation training: simulation in the surgery. Br J Gen Pract 2017;67:25.

24. Theilen $\mathrm{U}$, Leonard $\mathrm{P}$, Jones $\mathrm{P}$, et al. Regular in situ simulation training of paediatric medical emergency team improves hospital response to deteriorating patients. Resuscitation 2013;84:218-22.

25. Ellis D, Crofts JF, Hunt LP, et al. Hospital, simulation center, and teamwork training for eclampsia management: a randomized controlled trial. Obstet Gynecol 2008;111:723-31.

26. Vanderwielen LM, Vanderbilt AA, Dumke EK, et al. Improving public health through student-led interprofessional extracurricular education and collaboration: a conceptual framework. J Multidiscip Healthc 2014;7:105-10.

27. Sargeant J, Loney E, Murphy G. Effective interprofessional teams: "contact is not enough" to build a team. $J$ Contin Educ Health Prof 2008;28:228-34.

28. Oxelmark L, Nordahl Amorøe T, Carlzon L, et al. Students understanding of teamwork and professional roles after interprofessional simulation-a qualitative analysis. Adv Simul 2017;2:8.

29. Qayumi K, Pachev G, Zheng B, et al. Status of simulation in health care education: an international survey. Adv Med Educ Pract 2014;5:457-67.

30. Ward J, McMurray R. The unspoken work of general practitioner receptionists: a re-examination of emotion management in primary care. Soc Sci Med 2011;72:1583-7.

31. Eisner M, Britten N. What do general practice receptionists think and feel about their work? Br J Gen Pract 1999;49:103-6.

32. McNeil KA, Mitchell RJ, Parker V. Interprofessional practice and professional identity threat. Health Sociology Review 2013;22:291-307. 